\title{
Moving Towards Self-actualization: \\ A Trauma-Informed and Needs-Focused Approach to the Mental Health Needs of Survivors of Commercial Child Sexual Exploitation
}

\author{
Julie Anne Laser-Maira \\ University of Denver, Graduate School of Social Work \\ Donna Peach \\ Department of Social Work, University of Salford, UK
}

Charles E. Hounmenou

Jane Addams College of Social Work, University of Illinois at Chicago, USA

Received: August 1, 2019 Accepted: September 10, 2019 Published: September 12, 2019

doi:10.5296/ijsw.v6i2.15198 URL: https://doi.org/10.5296/ijsw.v6i2.15198

\begin{abstract}
There is increasing evidence that children who are subject to commercial child sexual exploitation (CCSE) are likely to experience complex mental health needs. Failure to address the trauma experienced by victims of CCSE can lead to suicide attempts, self-harm, and long-term mental health needs (Powell, Asbill, Louis, \& Stoklosa, 2018). A 'trauma-informed' approach (TIA) creates a responsive environment that improves the motivation of victims of CCSE to seek treatment and service providers to address unmet needs. Merging Maslow's (1943) hierarchy of needs with a TIA approach provides a comprehensive framework to assess the service requirements necessary to meet CCSE survivors' needs. Particularly, when Maslow's hierarchy of needs model is coupled with contemporary extensions, which address our greater understanding of the neurological impact of abuse on physiological well-being greater resilience can be created. Additionally, a TIA instigates a shift from victims of CCSE being viewed as damaged, to an understanding of the impact abusive experiences have had on their development. That approach permits them and
\end{abstract}


others to perceive their "survivorhood" and develop their capacity to achieve self-actualization. This paper critically examines what is constituted as best practice in trauma-informed mental health service delivery to not only meet needs but to support CCSE survivors' attainment of self-actualization.

Keywords: Child, CCSE (Commercial Child Sexual Exploitation), Survivors, Mental health, Hierarchy of needs, Best practices

\section{Introduction}

Recurrent acts of physical abuse, emotional abuse, and sexual violence experienced by children have significant repercussions on their mental health and can alter their short and long-term behavior (Oram, Khondoker, Abas, Broadbent, \& Howard, 2015). The resultant complex needs suggest that in order to best support survivors of CCSE, comprehensive services that include both mental health and physical health services, should be consistently provided (Levine \& Schumacher, 2017; Powell, Asbill, Louis \& Stoklosa, 2018; Rafferty 2018). Thus, the complexity of CCSE survivor's needs will likely require specialized services. However, foundational to the premise that survivors are supported to access services, which aid their physical and psychological recovery, means first having their primary needs met. More specifically, CCSE survivors need individualized care that uniquely tailors each child's care and treatment plan (Hom \& Woods, 2013; Rafferty 2018). Worryingly, it has been suggested that a lack of continuity of care increased the likelihood that survivors will return to the life (become re-victimized by CCSE; Domoney, Howard, Abas, Broadbent \& Oram, 2015). Therefore, we proffer a framework that considers the positionality of CCSE in relationship to Maslow's (1943) hierarchy of needs when considering trauma-informed clinical mental health interventions.

\section{Scoping the Need for a Comprehensive Service}

Human trafficking is clandestine, and as reliable international estimates are difficult to obtain (Greenbaum \& Crawford-Jakubiak, 2015), we are yet to understand the extent to which children are exploited. However, the International Labour Organization suggests approximately 211 million children are subject to exploitative economic practices (ILO, n.d.). More specifically, the United Nations Office on Drug and Crime (UNODC, 2016) evaluation of international data found that worldwide more than half of the victims (54\%) are sexually exploited, 38\% experienced forced labor, and $8 \%$ other forms of trafficking (e.g., organs, tissue, babies). In addition, the UNODC reported that across the world $42 \%$ of victims were trafficked domestically, thus never leaving their country (UNODC, 2016). Therefore, many victims and traffickers share the same language and ethnicity, which makes exploitation by traffickers easier since they can generate greater trust and may even be acquainted with the victim's family (UNODC, 2016).

In regional studies completed in Eastern and Southern Africa, UNICEF found 36\% of youth age 5-14 years old were involved in CCSE (UNICEF, n.d.). CCSE in the U.S. has been estimated from 1,400 to 2.4 million, leaving it up to anyone's guess where the actual numbers are (U.S. Department of Justice, Office of Juvenile Justice and Delinquency Prevention and National Academies, 2013). The National Crime Agency in the UK began to collate and publish the number of people who were thought to be victims of human trafficking in 2012; 


\section{Macrothink}

International Journal of Social Work

ISSN 2332-7278

2019, Vol. 6, No. 2

between 2012 and 2018, a total of 20,480 children were identified as being subjected to child sexual exploitation in the UK (UK National Crime Agency, n.d.). Obviously, one cannot extrapolate regional numbers internationally, but it is safe to assume that CCSE is a huge issue everywhere.

Therefore, the challenge for health and mental health professionals is to resource a comprehensive service that meets the individual needs of innumerous survivors. The lack of coordination of resources may make getting comprehensive services for the survivor nearly impossible (Domoney, Howard, Abas, Broadbent \& Oram, 2015; Powell, Asbill, Louis \& Stoklosa, 2018). Furthermore, services that are insensitive to culture, gender, language, citizenship status may make seeking and receiving services unobtainable or fraught with fear (Clawson, Salomon \& Grace, 2008; Domoney, Howard, Abas, Broadbent \& Oram, 2015; Ijadi-Maghsoodi, Bath, Cook, Textor, \& Barnert, 2018; Powell, Asbill, Louis \& Stoklosa, 2018). Long wait lists may delay or extinguish the need to seek services (Domoney, Howard, Abas, Broadbent \& Oram, 2015).

Delivering an individualized approach requires an extension of usual case management designed to combine the myriad of survivor needs with a trauma-informed service level approach to recovery (Rafferty, 2018). Importantly, this includes meeting the immediate needs of the victim such as food, shelter, clothing, and obtaining identification (Hardy, Compton \& McPhatter, 2013; Hom \& Woods, 2013). In Figure 1, Maslow's (1943, 1987) conceptualized model of five areas of human need (physiological, safety, social, self-esteem, and self-actualization) is depicted. Physiological needs (e.g., food, drink, shelter, clothing, warmth, sleep) are first level needs and the most important ones for survival; all the other needs become secondary till the physiological needs are met. Safety needs (e.g., protection, safety, law, well-being, stability, freedom from fear) are conceptualized as the second level needs. The third level of human needs is social, and involves feelings of love, being part of a group, belongingness, trust, acceptance, and relationship. The next level of human needs is related to self-esteem (dignity, achievement, independence, industry) and desire for respect. The last level of human needs - self-actualization-is to realize personal potential, self-fulfilment, seeking personal development, and desiring to thrive and achieve everything one is able to (Maslow, 1987). 


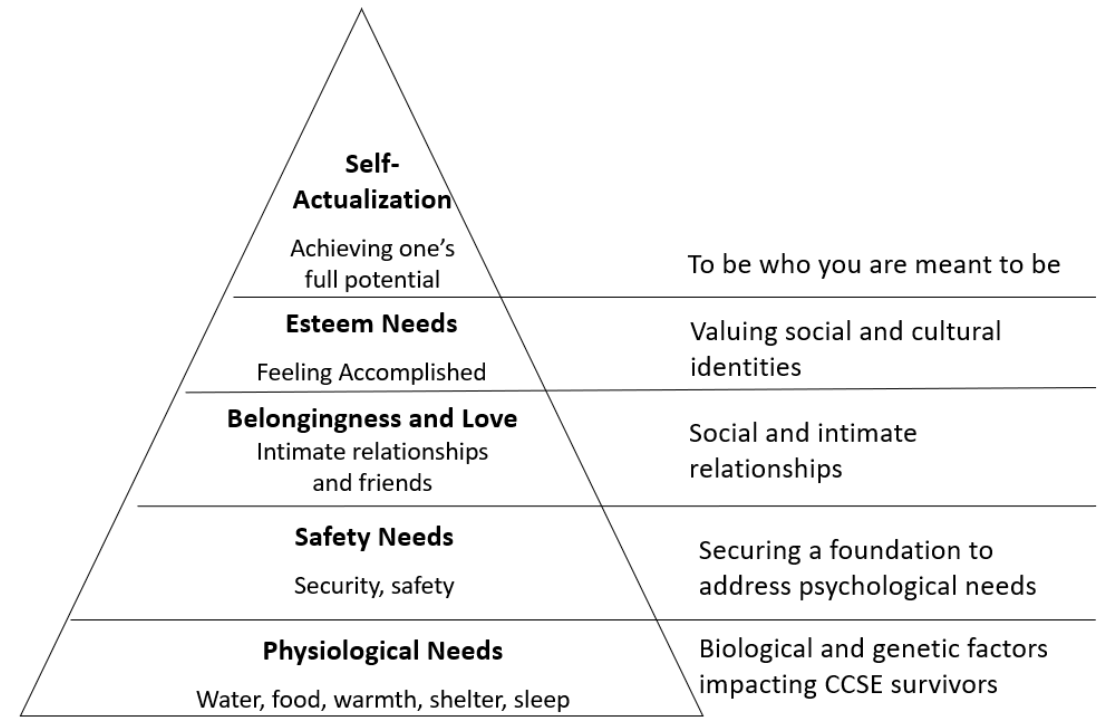

Figure 1. Maslow’s hierarchy of needs (adapted from Maslow, 1943)

A traditional service response to the mental health needs of CCSE survivors might begin to address the second level of needs (i.e., safety) and third level of needs (social) rather than the first level (physiological) of the Maslow's hierarchy. Arguably, a comprehensive trauma-informed approach should consider these higher-level needs as secondary to assessing and addressing survivors' basic needs including water, food and a secure home. Thus, best practice supports service providers working collectively with the survivor wherever their needs are identified. We argue that in order to support the CCSE victim to transition to survivor, it is important to nurture their ambition to thrive and reach their full potential.

\section{Physiological Needs: Biological and Genetic Factors Impacting CCSE Survivors}

Addressing CCSE survivors' mental health needs is important, but responding first to their basic needs such as food, housing and is crucial for their survival. Studies with service providers as participants have often stressed CCSE survivors' mental health service needs (Clawson, Salomon, \& Grace, 2008; Countryman-Roswurm, \& Shaffer, 2015; Greenbaum \& Crawford-Jakubiak, 2015; Hardy, Compton, \& McPhatter, 2013; Hossain, Zimmerman, Abas, Light, \& Watts, 2010; Levine \& Schumacher, 2017; Oram et al., 2015; Rafferty, 2018). However, many CCSE victims are trapped in the sex trade due to poverty and other vulnerability factors (e.g., childhood experiences of sexual abuse, limited education, and homelessness) linked to basic human needs (Clawson, Salomon, \& Grace, 2008; Dank et al., 2015; Greenbaum \& Crawford-Jakubiak, 2015; Laser-Maira, Huey, Castro, Ehrlich, \& Nicotera, 2018; Laser-Maira, Huey, Castro, \& Ehrlich,, 2016; Naramore, Bright, Epps, \& Hardt, 2017; Roe-Sepowitz, 2012; Steiner et al., 2018). In studies of survivors as participants, food, housing and job opportunities were stated as their primary needs (Estes \& Weiner, 2001; Curtis, Terry, Dank, Dombrowski, \& Khan, 2008; Hounmenou \& Her, 2018; Laser-Maira, Huey, Castro, Ehrlich, \& Nicotera, 2018; Maney et al., 2011; Swaner et al., 2016).

The base of Maslow's hierarchical pyramid (Figure 1) is a person's 'physiological' needs (e.g., food, drink, shelter, clothing, warmth, sleep), which are first level needs and the most 
important ones, as discussed above. Although human primary needs remain the same over time, modern theoretical and technological developments permit a greater understanding of our biological and genetic physiology. Kenrick, Griskevicius, Neuberg and Schaller (2010) suggest these contemporary physiological factors serve to extend the foundation and application of Maslow's pyramid of needs.

Upon a review of the literature, Levine and Schumacher (2017) argued that biological and genetic factors could partly explain how CCSE and subsequent mental illness seem inevitably connected. Psychological abuse experienced during sexual exploitation "is associated with neurochemical and structural changes in the brain; more so because many sex trafficking victims are children" (Levine \& Schumacher, 2017, p. 2). Thus, the developing brain is impacted by CCSE causing biological differences in the brains of those who survive (Levine \& Schumacher, 2017). In addition to their experience of sexual exploitation, survivors may have experienced other forms of childhood abuse, but they are resilient because of the potential for brain plasticity (i.e., the ability of the brain to adapt; Anderson, Spencer-Smith, $\&$ Wood, 2011). However, brain plasticity is moderated by the severity of abuse, age, socio-demographic factors, family history, and interventions (Anderson, Spencer-Smith, \& Wood, 2011).

Levine and Schumacher (2017) found that those victimized by CCSE are likely to be from families with a high prevalence of depression, schizophrenia, and substance abuse. Likewise, survivors may have been immersed in a social environment of harmful factors such as poverty, crime, drug abuse, and violence (Levine \& Schumacher, 2017). Additionally, research showed that lower levels of social support and lack of adequate responses to basic social needs also put survivors of sex trafficking at greater risk for mental illness (Abas et al., 2013; Domoney et al., 2015). Altun et al. (2017) found that social stressors (e.g., unstable housing, insecure immigration status) are likely to exacerbate distress and psychological symptoms. Thus, prior to being trafficked, survivors were often at risk for mental health issues due to family history and their social environment, which are then exacerbated by the trauma of being sexually exploited.

In addition to potential pre-existing vulnerabilities, it is unsurprising that after being possibly tricked, trapped, tortured, traded, and traumatized through the use of force, coercion, and/or fraud, that those who are victimized experience not only physical harm, but also psychological consequences (Greenbaum \& Crawford-Jakubiak, 2015; Levine \& Schumacher, 2017; Oram et al., 2015; Rafferty, 2013; Rafferty, 2018; Stoklosa, MacGibbon, \& Stoklosa, 2017; Sweeney, Filson, Kennedy, Collinson \& Gillard, 2018; Williamson, Dutch, \& Clawson, 2008). In practice, we need to bear witness to the aftermath of CCSE with Stoklosa et al. (2017), reporting that victims of sex trafficking are very likely to experience a sexual, physical, verbal, or psychological assault on a daily or even hourly basis. In fact, as a multi-faceted stressor, CCSE can cause many psychological issues including, but not limited to: depression, mood disorders, anxiety disorders, insomnia, dissociative disorders, affective disorders, substance-related disorders self-mutilation, low self-esteem, and complex trauma (Countryman-Roswurm \& Shaffer, 2015; Domoney, Howard, Abas, Broadbent, \& Oram, 2015; Greenbaum \& Crawford-Jakubiak, 2015; Hossain, Zimmerman, Abas, Light, \& Watts, 2010; Clawson, Dutch \& Williamson, 2008; Levine \& Schumacher, 2017; Oram, Khondoker, Abas, 
Broadbent, \& Howard, 2015; Rafferty, 2013; Rafferty, 2018). Other factors commonly noted for survivors include attention deficit hyperactivity disorder, conduct disorder, antisocial personality traits, and impulse control (Hardy, Compton, \& McPhatter, 2013; Ottisova, Smith, Shetty, Stahl, Downs, \& Oram, 2018; Williamson, Dutch, \& Clawson, 2008).

Most survivors need counseling services that focus on depression, anxiety, dissociation, PTSD (Post-traumatic Stress Disorder), complex trauma, and DESNOS (Disorder of Extreme Stress; Hardy, Compton \& McPhatter, 2013; Hom \& Woods, 2013; Levine \& Schumacher, 2017), and evaluate for self-harm and suicidality (Hardy, Compton, \& McPhatter, 2013; Ottisova, Smith, Shetty, Stahl, Downs, \& Oram, 2018). Survivors may also need alcohol and drug abuse counseling (Greenbaum \& Crawford-Jakubiak, 2015; Hardy, Compton \& McPhatter, 2013; Levine \& Schumacher, 2017; Ottisova, Smith, Shetty, Stahl Downs, \& Oram, 2018). Physical health service needs include physical exams to rule out vitamin deficiencies, physical abuse (including broken bones, lacerations, and burns), infectious diseases (including tuberculosis, HIV, STDs/STIs, Hepatitis B and C), gynecological issues, cardiovascular hypertension, chronic pain syndrome, asthma, diabetes, lice and other pests (Greenbaum \& Crawford-Jakubiak, 2015; Levine \& Schumacher, 2017). Meeting these primary needs are complicated for survivors because their lives may continue to be threatened by traffickers. Despite these concerns, Lederer and Wetzel (2014) reported 80\% of their participants $(n=106)$ accessed a health care provider during their exploitation. Thus it is important to consider that current patients may be victims of CCSE and are not able or ready to seek on going services.

\section{Need for Safety: Securing a Foundation to Address Psychological Needs}

The lack of a safe foundational base makes CCSE survivors highly vulnerable to various mental health consequences. In their retrospective study of 84 adolescent patients, Varma, Gillespie, McCracken and Greenbaum (2015) found survivors of CCSE had their safety threatened by a heightened exposure to violence and were often missing from home. In particular, safety is a vital issue for the majority of trafficking victims who are crossing borders due to conflict, violence, persecution, human rights violations, or economic devastation (UNODC, 2016). Regrettably, if trafficking victims are perceived as foreign, or coming from religious traditions that reduce traffickers' feelings of compassion and may increase brutality (Burke, 2015; Global Detention Project, 2018; Walk Free Foundation, 2014). Thus, the immediate needs of trafficking victims, include having access to a place of safety, medical treatment, legal support, and a translator/interpreter (Macy \& Johns, 2011). However, access to health-care does not necessarily equate to safety as victims report that, even when traffickers did permit them to access health-care, they continued to be closely monitored (Westwood et al., 2016).

This all-consuming nature of abuse calls for a holistic consideration of survivors' needs, and we suggest that service provision for survivors has to be all-inclusive. However, a CCSE survivor who was trafficked into a foreign country is likely to also experience isolation and fear of deportation, which threatens their need for safety (Polaris, 2010). The threat to a basic need for safety creates further vulnerabilities for CCSE survivors who require a significantly longer duration of contact with mental health services compared to those who had not been trafficked (Ottisova et al., 2018). Conversely, Williamson, Dutch, and Clawson (2010) argued 
that the majority of children who have been sexually assaulted or exploited do not benefit from long-term therapy. These authors suggest any therapy for these children had to strike a balance between not being so short-term and symptom-driven, and not being exceedingly long to keep child survivors in therapy beyond necessary, which coincides with best practices for children's therapy in general (Laser \& Nicotera, 2011). Regardless of longevity of clinical therapy, as points of contact, health care centers provide a basis for initiating the foundational messages, which can lead them to seek safety. However, access issues for non-native survivors who might be reluctant to risk discovery and subsequent deportation from the receiving country is always an issue (Surtees, 2006).

Research also shows that even the environment supposed to provide a safe space and protection to CCSE survivors is sometimes a risk for developing mental health problems (Rafferty, 2018). Rafferty (2018) found that CCSE survivors in aftercare residential programs experienced other mental health related issues including self-harming behaviors, acting-out behaviors associated with living in a shelter, sexual harassment, perpetrating abuse on younger peers, and flirtatious behavior. The study found that the stressful environment of some residential facilities contributed or compounded to the children's mental health problems (Rafferty, 2018).

The emerging picture created is that many CCSE survivors experience complex trauma. Complex trauma refers to a type of trauma that occurs repeatedly and cumulatively, within specific relationships and contexts, and over a period of time (Countryman-Roswurm \& Shaffer, 2015; Courtois, 2004). In the case of child abuse, the survivor's development is often seriously compromised by repetitive abuse and inadequate response at the hands of people for whom he or she relies for safety and protection (Courtois, 2004). In addition, survivors reported concerns about protecting their confidentiality; thus, they would avoid sharing their mental health concerns to prevent this information being recorded into their residential home's records (Ijadi-Maghsoodi, Bath, Cook, Textor, \& Barnert, 2018). Furthermore, the fear of criminal prosecution may reduce the survivor's desire to enter or continue in treatment (Domoney, Howard, Abas, Broadbent, \& Oram, 2015). Notably, when CCSE survivors are unable to rely on public services for safety and protection, they risk increasing their posttraumatic stress.

Posttraumatic stress disorder (PTSD) and complex PTSD (CPTSD) have been identified across a number of studies as the most common mental health problems experienced by sex trafficking survivors (Countryman-Roswurm \& Shaffer, 2015; Courtois, 2008; Domoney et al., 2015; Hardy, Compton, \& McPhatter, 2013; Rafferty, 2018). CPTSD is an anxiety disorder marked by re-experiencing of a traumatic event such as extreme fear, horror, helplessness, entrapment, relocation, and exposure to various types of abuse (Countryman-Roswurm \& Shaffer, 2015, Courtois, 2008). CCSE survivors experiencing PTSD or CPTSD are likely to display three categories of symptoms: (1) intrusive re-experiencing of the trauma; (2) dissociation or emotional numbing; and (3) physiological hyperarousal (Clawson, Salomon \& Grace, 2008; Countryman-Roswurm \& Shaffer, 2015). Each of these symptoms erode the ability of the survivor to feel safe, thus the need to feel safe is paramount. 


\section{Need for Belongingness and Love: Social and Intimate Relationships}

The factors that feed the proliferation of trafficking often mean victims of CCSE are socially isolated and living in impoverished communities (Hom \& Woods, 2013). Gjermeni and Van Hook (2012) explored the contribution of faith-based programs to support CCSE survivors in Albania. The principle of their approach was the recognition of the importance of equal value for all people and the negative consequences of widespread patriarchal persecution of women. Thus, beyond food, housing and mental health services, CCSE survivors have a need for education, job skills training, employment, housing, mentoring, and navigating the court system (Gjermeni \& Van Hook, 2012; Hardy, Compton, \& McPhatter, 2013; Hom \& Woods, 2013). Providing the opportunity for a survivor to reveal their experience of relationships should form part of any initial mental health assessment (Rafferty, 2018), and should include their child abuse history and intimate partner violence (IPV) history (Hardy, Compton, \& McPhatter, 2013; Hom \& Woods, 2013; Ottisova, Smith, Shetty, Stahl, Downs, \& Oram, 2018). These relationships can have been positive or negative. It is important to note that these relationships have contributed to their own life story and understanding of how relationships work.

A sense of belongingness and love should also include the survivor's love of their embodied self. Experiences of physical and psychological trauma can affect the relationship CCSE survivors have with their body, and dance therapy has been shown, for some, to be a transformative medium (Schrader \& Wendland, 2012). Creative group dance activities provided survivors with opportunities to gain control of their bodies and to increase their confidence and ability to use expressive movement (Gray, 2001). Experiential therapy, which can be a guided activity, a game, a mental puzzle to work out, time in nature, or a physical challenge with a clinician, can increase well-being and resilience (Laser-Maira, 2016; Nicotera \& Laser-Maira, 2017). The experience of experiential therapy that the client participates in usually push them out of their comfort zone and into a place of new insights into how to cope with issues effecting them (Laser-Maira, 2016; Nicotera \& Laser-Maira, 2017). Thus non-traditional therapies may be of great value to CCSE survivors where talk-therapy may not be most effective. For instance, a music therapy program as a means of support for survivors in Cambodia demonstrated its capacity as a useful therapeutic tool with children (Schrader \& Wendland, 2012). Non-traditional therapies were especially important for children for whom language is a barrier to their engagement with talking therapy (Lefevre, 2004). Additionally it was found, if survivors do share a common language, the physiological benefits of singing can help reduce stress, and singing in a group counters the isolation experienced by CCSE survivors (LaVerdiere, 2007).

According to Clawson, Salomon, and Grace (2008), the therapeutic relationship between survivors and service providers should be collaborative. In this relationship, both the survivor and the provider share valuable knowledge; the survivor can be both an active planner and participant in services, and a priority is placed on choice, and trust developed over time (Clawson, Salomon, \& Grace, 2008). Country-Roswurm and Shaffer (2015) proposed a model designed for collaborative services called Lotus Anti-Trafficking Victim to Vitality Program Model. The model has been used in various ways, including anti-trafficking multidisciplinary survivor-led case planning, individual and family therapy, psycho-educational peer groups, 
and therapeutic staff-secure residential settings (Country-Roswurm \& Shaffer, 2015). The core principles of the Lotus Collaborative Program Model include the development of transformational relationships, safety and predictability, grace and forgiveness for oneself and others, and multifaceted healing practices that are facilitated to address the complex trauma associated with CCSE (Country-Roswurm \& Shaffer, 2015). The model, which aims to address trauma associated with sex trafficking holistically, includes services such as therapeutic, mental/emotional care, and residential treatment.

Common in the literature for more mainstream approaches for clinical interventions is the talk therapy approach of Trauma-Focused Cognitive Behavioral Therapy (TF-CBT; Cary \& McMillen, 2012; Cohen, Berliner \& Mannarino, 2010; Cohen, Deblinger, Mannarino, \& Steer, 2004). TF-CBT is a widely used and effective therapeutic approach with children and young people who have experienced trauma (Cary \& McMillen, 2012; Cohen, Berliner \& Mannarino, 2010; Cohen, Deblinger, Mannarino, \& Steer, 2004). Exploring relationships as a means of meeting the needs of CCSE survivors should include the role and function of those involved in the therapeutic process. Hughes, Bean and Harper (2015) suggest the role of the TF-CBT therapist is fundamental to the female adolescent survivor of sexual abuse, to her capacity to engage with talk therapy. Thus it is often the relationship that is forged between the therapist and client that supports growth in the client. In addition, Hughes, Bean and Harper (2015) also reported on the useful incorporation of family and peer group support to help address individual and systemic issues as they arise. TF-CBT interventions can include and benefit not only the child survivor, but also their family members, which potentially co-create an infrastructure of support and recovery for the whole family. Hughes, Bean and Harper (2015) reported positive outcomes for family systems approaches to TF-CBT. This inclusive approach could readily be extended to include guardians for children living in foster or residential care settings. However, there is an absence of evidence to explore the potential impact of the temporality of non-familial relationships that children who have been trafficked might experience when engaging in therapy.

\section{Need for Esteem: Valuing Social and Cultural Identities}

It is important that the range of support available is compatible with the diverse cultural needs of those who have been victimized (McIntyre, 2014). Application of Western mental health models to child survivors of sex trafficking in developing countries or those trafficked into other countries calls for consideration of cultural values specific to the children. Williamson, Dutch and Clawson (2010) argued that ethnicity could influence how people seek assistance, attribute psychological difficulties, experience trauma, and perceive recovery options. Likewise, they suggest ethnicity can affect survivors' perceptions about their pain, their expectations of mental health treatment, and beliefs about the best course of treatment for them (Williamson, Dutch, \& Clawson, 2010). Consequently, it is important to be aware that every culture has a distinct perspective on mental health and distinct beliefs about the benefits or stigma of seeking mental health services.

The knowledge base on mental health as related to CCSE in developing countries is very limited (Ennew, 2008). Hounmenou and Her (2018) found little evidence of the use of mainstream trauma-focused interventions for children survivors of CCSE in Sub-Saharan Africa. Even when mental health practitioners had skills to provide mental health services to 
CCSE survivors, they tended to rely on interpretations of symptoms based on Western mental health theories and gave little attention to culturally appropriate concepts of treatment that involved both the individual and the entire community (Hounmenou \& Her, 2018). According to Rafferty (2018), interventions that were reported as promising in Western countries might not be effective elsewhere or might require substantial modification of their underlying concepts to ensure that they were consistent with local customs and beliefs. Mainstream trauma-focused interventions were not always culturally appropriate or valid in developing countries, and are not always the most effective or suitable approaches for use in Eastern cultures (Rafferty, 2018). Some cultures do not discern psychological, emotional, and spiritual reactions from physical ones (Rafferty, 2018). That is important especially when feelings of shame, stigma or feeling judged can keep survivors from seeking treatment or continuing treatment (Hardy, Compton, \& McPhatter, 2013; Hom \& Woods, 2013; Ijadi-Maghsoodi, Bath, Cook, Textor, \& Barnert, 2018; Powell, Asbill, Louis \& Stoklosa, 2018).

Worryingly, therapies with a lot of empirical support from developed countries often lack support in countries where cultural pressures exist to dissimulate mental health problems (Rafferty, 2018).

Rafferty $(2013$, 2018) stressed the importance of incorporating alternatives to traditional mental health services that are culturally relevant for the treatment of children with complex psychological and social need as a vital element of good practice. Recommendations for culturally sensitive treatment for CCSE survivors stressed the importance of considering transcultural mental health care, which are services that are culturally sensitive and involve staff who are culturally competent with the necessary skills and abilities to provide optimal care for the children in their care (Rafferty, 2018). There is a need to ensure that care programs are appropriate and consistent with local intervention theory, standards, and best practices (Rafferty, 2018). Additionally, potentially promising programs should be viewed within the context of cultural traditions (Rafferty, 2018). Interestingly, Clawson, Dutch, Salomon, and Grace (2009) found that using alternative treatments such as religious or spiritual activities, ritual cleanings, acupuncture, meditation, and music/art/experiential therapy appeared to improve CCSE survivor recovery and outcomes more than traditional talk therapy mental health treatments.

There are multiple reasons why we should consider 'alternative' modes of support for those who have experienced CCSE; firstly, provision of mental health services is often limited by economic, social, cultural and geographical factors (Gjermeni \& Van Hook, 2012). The lack of financial resources to seek treatment may make it impossible for the survivor to enter into therapy (Clawson, Salomon \& Grace, 2008; Domoney, Howard, Abas, Broadbent \& Oram, 2015; Powell, Asbill, Louis, \& Stoklosa, 2018; Rafferty, 2018). Even when services are free or at reduced costs, lack of eligibility of services may also serve as a roadblock to obtaining services (Domoney, Howard, Abas, Broadbent, \& Oram, 2015; Powell, Asbill, Louis \& Stoklosa, 2018). Secondly, the evidence shows that not everyone has access to mental health treatment, nor confidence in the quality of its delivery. Ijadi-Maghsoodi et al. (2018) found that some children only had access to treatment when they were in a foster care home or in a detention center and were less likely to have access to such a provision when they were living in the community. Finally, we are beginning to have some understanding of the barriers to 
treatment, but only from those who have (eventually) been able to access a service (Hardy, Compton \& McPhatter, 2013; Ijadi-Maghsoodi, Bath, Cook, Textor, \& Barnert, 2018). Thus we do not fully understand the need for services.

\section{Need for Self-actualization: To Be Who You Are Meant to Be}

As with all of life's significant experiences, the impact of CCSE changes the lives of those who survive it. Maslow suggested a musician needed to make music and an artist to create art (Maslow, 1943). For many CCSE survivors, self-actualization is associated with being a survivor. That concept is demonstrated in Bruhns et al.'s (2018) qualitative study of 11 female adult survivors of CCSE aged between 18 and 30 years old, who had been victimized between 2 and 10 years. Bruhns et al. (2018) reported that an integral part of their participant's self-concept was how their exploitation had motivated them to help others who had similar experiences. One of their participant's remarked:

I don't think I could do anything else. ... It's just; my own capacity to live and be free is really connected to other people's capacity to be free. ... It's sort of like, how do we enjoy our own freedom when we know others are enslaved? (Bruhns et al., 2018, p. 426).

Other women participants in Bruhns et al. (2018) described their experience of a transition in their self, from a person who did not value their own happiness as much as other peoples' happiness; whereas now they had a determined focus on their own personal and professional ambitions. Similarly, Corbett (2018) conducted interviews with 13 adult female survivors of CCSE who were not in contact with social services during their exploitation. Thus, their access to services occurred after exiting exploitation. Interestingly, Corbett (2018) reported the narrative of one participant named Jayla. The narrative below suggests that even during her exploitation Jayla was striving to achieve self-actualization, even though that was limited to the criminality of the world she was trapped in. Jayla describes seeing her advancement as gaining authority and selling drugs. However, upon exiting the life she reflects that her potential was constrained during her exploitation and that now she has survived an experience for which she had no preparation for how to survive.

We are survivors. Strong soldiers in a long hard war, but the outcome is that we are glad to survive and defeat what was designed to break us. It fits me because I could have let it take me down and lose myself. I survived something I didn't know how to prepare to survive.

I took a chance believing that it was something to advance my level in the game (I wanted to sell drugs) and be more of a boss. But I survived because it was designed to break me and weaken my mind as a woman and what my chances at life could be-Jayla. (Corbett, 2018, p. 97).

At this early stage of research inquiry into CCSE, few studies have been undertaken which focus on the future outcomes for survivors once the deficit in their needs has been satisfied. However, in addition to academics providing a platform to survivors, some are realizing their potential in creating their own literature. Palmer and Foley (2017) undertook a thematic analysis of some of these texts. Although, they note the limitations of memoirs as a data source, they find several authentic themes that provide individual insight into aspects of self such as resilience and the ongoing demands on survivors' post exploitation such as enduring judicial investigations. Notably, the end of the life for some is not realized until the 
announcement of their perpetrator's guilty verdict. One of the key learning points, which emanates from all papers that rely on survivors' experiences, is the role of survivors as educators for multi-disciplinary practitioners. Thus the transition from victim to survivor, though long and arduous can support growth that allows the survivor to be the person they should have always become.

\section{Implications for Practice}

There remains a paucity of knowledge of what is good evidence-based therapy for children and young people who have been trafficked and subject to sexual exploitation (Ijadi-Maghsoodi, Cook, Barnert, Gaboian, \& Bath, 2016). This is exacerbated as studies reported inadequate specialist training for trauma among mental health providers (Beck et al., 2015; Coverdale, Beresin, Louie, Balon, \& Roberts, 2016). Notably, traditional mental health service models that work with adult survivors of sex trafficking have not been effective in addressing the complex mental health needs of child survivors of CCSE (Clawson, Dutch, Salomon \& Grace, 2009). Applying knowledge into our practice can be daunting and it is important that service providers ensure that practitioners have sufficient training and support. Some survivors who access clinical services may find it difficult to get support they need because mental health care workers lack the training of the special issues that effect survivors (Clawson, Salomon, \& Grace, 2008; Powell, Asbill, Louis, \& Stoklosa, 2018; Rafferty, 2018). Furthermore, many survivors are aware of this deficit in service provision and participants in Ijadi-Maghsoodi et al.'s (2018) study were concerned about the quality of services available to them delivered by college students at the care home, and that these services were not specific to the needs of young people but for adults. Furthermore, once therapy commences, the lack of feelings of belonging and connection to mental health providers may contribute to a lack of attendance at therapy (Hardy, Compton, \& McPhatter, 2013). Further barriers to accessing services included fear of being identified by traffickers (Ijadi-Maghsoodi, Bath, Cook, Textor, \& Barnert, 2018).

For child survivors of CCSE, it is important to create a trauma-informed care plan that take into account the following essential steps: (1) understanding the impact of violence and victimization on the client's well-being; (2) knowing that the process of recovery from trauma is a primary goal of the treatment; (3) implementing an empowerment model that stresses the client's right to self-determination in the recovery process and emphasize their strengths and resilience;(4) acknowledging the cultural uniqueness of each client; and (5) involving the client in a collaborative relationship and development and evaluation services (Elliot et al. as cited in Hardy, Compton \& McPhatter, 2013). By following these steps greater self-actualization can be found in the survivor.

As clinicians who have worked with these traumatized children and youth we found that there are some simple phrases and conceptualizations that help to connect to survivors and their lived experiences. First, it is important as the clinician to remind oneself of how similar you are to the person sitting across from you; use your humanity as a bridge to create trust and rapport; acknowledge the survivor's resilience and strength for initially seeking out services and continuing to pursue services. The clinician needs to approach the survivor with patience; they are not on your timeline for recovery, you are on theirs (Hom \& Woods, 2013). Good trauma-informed practice takes time and moves at the pace of the client, if you push the pace, 
they will not return for future services. The clinician needs to understand that the trauma bond, also termed as Stockholm Syndrome, the survivor feels for their perpetrator is real (Hardy, Compton, \& McPhatter, 2013). Therefore, in therapy, it takes time for the survivor to reestablish trust with others and for some time the survivor may defend/protect their perpetrator even when they were treated badly by them. It is important when validating their experience as a survivor to acknowledge that they are the experts of their own life (Hom \& Woods, 2013). The clinician needs to become comfortable to sit with other people's pain, not to fix, but to bear witness to the experiences of the lives. Simple phrases like "it looks like your heart hurts" can help them begin to conceptualize the many and often conflicting feelings they are experiencing. Finally, over time, we should help the survivor uncover and validate the meaning of his or her own story (Hom \& Woods, 2013). Mental health services are a key ingredient to survivors becoming resilient. However, it needs to be done after their physiological and safety needs have been considered.

\section{Conclusion}

Fundamental to CCSE survivors feeling valued and achieving self-actualization is the availability and accessibility of trauma-informed services for all children regardless of their nationality, ethnicity, race, or country of origin. The primacy of ensuring that any survivor's physiological needs are met is foundational to their continued access to treatment. It is vital that services have an awareness of the continued threats to safety that survivors can experience from unmet needs that can arise from both traffickers and inadequate service delivery. Survivors need for belongingness and esteem requires a service that extends beyond a trauma response to one that facilitates educational and economic well-being. Importantly services and the research knowledge that supports them must be culturally diverse and inclusive. As survivors begin to add their own voice and knowledge to our shared understanding, we learn that despite the horrors of their experiences they continue to strive to be all that they are meant to be. As service providers, we need to do the same.

\section{References}

Abas, M., Ostrovschi, N. V., Prince, M., Gorceag, V. I., Trigub, C., Oram, S. (2013). Risk factors for mental disorders in women survivors of human trafficking: A historical cohort study. BMC Psychiatry, 13(204), 1-11. https://doi.org/10.1186/1471-244X-13-204

Altun, S., Abas, M., Zimmerman, C., Howard, L. M., \& Oram, S. (2017). Mental health and human trafficking: responding to survivors' needs. BJPsych International, 14(1), 21-23. https://doi.org/10.1192/S205647400000163X

Anderson, V., Spencer-Smith, M., \& Wood, A. (2011). Do children really recover better? Neurobehavioral plasticity after early brain insult. Brain, 134(8), 2197-2221. https://doi.org/10.1093/brain/awr103

Beck, M. E., Lineer, M. M., Melzer-Lange, M., Simpson, P., Nugent, M., \& Rabbitt, A. (2015). Medical providers' understanding of sex trafficking and their experience with at-risk patients. Pediatrics, 135(4), e895-e902. https://doi.org/10.1542/peds.2014-2814

Bruhns, M. E., Prado, A. del, Slezakova, J., Lapinski, A. J., Li, T., \& Pizer, B. (2018). Survivors' perspectives on recovery from commercial sexual exploitation beginning in 
$\begin{array}{llll}\text { childhood. The } \quad \text { Counseling } \quad \text { Psychologist, } & \text { 46(4), }\end{array}$ https://doi.10.1177/0011000018777544

Burke, D. (2015, May 1). How Hindus and Buddhists view Nepal's devastating earthquake. CNN News. Retrieved from http://www.cnn.com/2015/04/26/world/nepal-earthquake-buddhists-hindus/

Cary, C. E., \& McMillen, J. C. (2012). The data behind the dissemination: A systematic review of trauma-focused cognitive behavioral therapy for use with children and youth. Children and Youth Services Review, 34(4), 748-757. http://doi.org/10.1016/j.childyouth.2012.01.003

Clawson, H. J., Dutch, N. M., Salomon, A., \& Grace, L.G. (2009). Study of HHS programs Serving human trafficking victims. Final report. Washington, DC: U.S. Department of Health \& Human Services.

Clawson, N., Dutch, N. M., \& Williamson, E. (2008). National Symposium on the Health Needs of Human Trafficking Victims: Background Brief. Washington, DC: Office of the Assistant Secretary for Planning and Evaluation, U.S. Department of Health and Human Services.

Clawson, H. J., Salomon, A., \& Grace (2008). Treating the hidden wounds: Trauma treatment and mental health recovery for victims of human trafficking. Washington, DC: U.S. Department of Health \& Human Services.

Corbett, A. (2018). The voices of survivors: An exploration of the contributing factors that assisted with exiting from commercial sexual exploitation in childhood. Children and Youth Services Review, 85, 91-98. https://doi.org/10.1016/j.childyouth.2017.12.009

Cohen, J.A., Berliner, L., \& Mannarino A. P. (2010). Trauma focused CBT for children with co-occurring trauma and behavior problems. Child Abuse and Neglect, 34(4), 215-24. https://doi.org/10.1016/j.chiabu.2009.12.003

Cohen, J.A., Deblinger, E., \& Mannarino A.P. (2004). A multisite randomized controlled trial for children with sexual abuse-related PTSD symptoms. Journal of the American Academy of Child \& Adolescent Psychiatry, 43(4), 393-402. https://doi.org/10.1097/00004583-200404 000-00005

Courtois, C. A. (2004). Complex Trauma (2004). Complex reactions: Assessment and treatment. Psychotherapy: Theory, Research, Practice, Training, 41(4), 412-425. https://doi.org/10.1037/0033-3204.41.4.412

Countryman-Roswurm, K. I., \& Shaffer, V. A. (2015). 'It's more than just my body that got hurt:' The psychophysiological consequences of sex trafficking. Journal of Trafficking, Organized Crime and Security, 1(1), 1-8.

Coverdale, J., Beresin, E. V., Louie, A. K., Balon, R., \& Roberts, L. W. (2016). Human Trafficking and psychiatric education: A call to action. Academic Psychiatry, 40(1), 119-123. https://doi.org/10.1007/s40596-015-0462-2

Curtis, R., Terry, K., Dank, M., Dombrowski, K., \& Khan, B. (2008). Commercial sexual exploitation of children in New York City. Volume 1: The CSEC Population in New York City: Size, Characteristics, and Needs. U.S. Department of Justice. https://doi.org/10.1037/ e514232009-001 
Dank, M., Yahner, J., Madden, K., Bañuelos, I., Yu, L., Ritchie, A., \& Conner, B. (2015). Surviving the streets of New York: Experiences of LGBTQ youth, YMSM, and YWSW engaged in survival sex. Washington, DC: The Urban Institute.

Domoney, J., Howard, L. M., Abas, M., Broadbent, M., \& Oram, S. (2015). Mental health service responses to human trafficking: A qualitative study of professionals' experiences of providing care. BMC Psychiatry, 15(289), 1-9. https://doi.org/10.1186/s12888-015-0679-3

Ennew, J. (2008). Exploitation of children in prostitution. A paper presented at the World Congress III against the sexual exploitation of children and adolescents. Rio de Janeiro, Brazil, 25-28 November, 2008. Bangkok, Thailand. ECPAT International. Retrieved from http://www.ecpat.org.uk/sites/default/files/thematic_paper_prostitution_of_children.pdf

Estes, R. J., \& Weiner, N. A. (2001). The Commercial sexual exploitation of children in the U.S., Canada and Mexico. University of Pennsylvania School of Social Work Center for the Study of Youth Policy. 260 pages. Retrieved from https://abolitionistmom.org/wp-content/ uploads/2014/05/Complete_CSEC_0estes-weiner.pdf.

Gjermeni, E., \& Van Hook, M. (2012). Trafficking of human beings In Albania: The role of faith-based programs. Social Work \& Christianity: Journal of the North American Association of Christians in Social Work, 39(4), 435-448.

Global Detention Project. (2018). Joint Submission to the UN Committee on the Elimination of Racial Discrimination: Qatar. Retrieved from https://www.globaldetentionproject.org/submission-cerd-qatar

Gray, A. (2001). The body remembers: Dance/movement therapy with an adult survivor of torture. American Journal of Dance Therapy, 23(1), 29-43. https://doi.org/10.1023/A:101078 0306585

Greenbaum, J., \& Crawford-Jakubiak, J. (2015). Child sex trafficking and commercial sexual exploitation: Health care needs of victims. American Academy of Pediatrics. https://doi.org/10.1542/peds.2014-4138

Hardy, V., Compton, K., \& McPhatter, V. (2013). Domestic minor sex trafficking: practice implications for mental health professionals. Journal of Women and Social Work, 28(1), 8-18. https://doi.org/10.1177/0886109912475172

Hom, K. A., \& Woods, S. J. (2013). Trauma and its aftermath for commercially sexually exploited women as told by front-line service providers. Issues in Mental Health Nursing, 34(2), 75-81. https://doi.org/10.3109/01612840.2012.723300

Hounmenou, C., \& Her, W. (2018). Distinctiveness in the commercial sexual exploitation of children in sub-Saharan Africa: A Review of the Literature. Journal of Human Trafficking, 4(4), 298-326. https://doi.org/10.1080/23322705.2017.1365567

Hossain, M., Zimmerman, C., Abas, M., Light, M., \& Watts. C. (2010). The relationship of trauma to mental disorders among trafficked and sexually exploited girls and women. Am. J. Public Health, 100, 2442-49. https://doi.org/10.2105/AJPH.2009.173229

Hughes, A. a., Bean, R. A., \& Harper, J. M. (2015). Sexual abuse and subsequent risky sexual behaviors: A competency model for treatment of adolescent females. The American Journal of Family Therapy, 43(4), 326-338. http://doi.org/10.1080/01926187.2015.1051897 
Ijadi-Maghsoodi, R., Bath, E., Cook, M., Textor, L., \& Barnert, E. (2018). Commercially sexually exploited youths' health care experiences, barriers, and recommendations: A qualitative analysis. Child Abuse and Neglect, 76, 334-341. https://doi.org/10.1016/j.chiabu. 2017.11.002

International Labour Organization. (n.d.). Forced labour, modern slavery and human trafficking. Retrieved from http://www.ilo.org/global/topics/forced-labour/ lang--en/index.htm

Kenrick, D. T., Griskevicius, V., Neuberg, S. L., \& Schaller, M. (2010). Renovating the Pyramid of Needs: Contemporary extensions built upon ancient foundations. Perspectives on Psychological Science, 5(3), 292-314.

Laser, J., \& Nicotera, N. (2011). Working with adolescents: A guide for practitioners. New York: Guilford Press.

Laser-Maira, J. (2016). Children's Experiential Therapy Group in an Elementary School. Chapter 15. In W.Pelech, R. Basso, C. Lee \& M. Gandarilla. (Eds.) Inclusive Group Work. New York: Oxford Press.

Laser-Maira, J., Huey, C., Castro, O., Ehrlich, K., Nicotera, N. (2018). Human trafficking in Peru: Stakeholder perceptions of how to combat human trafficking and help support its survivors. Journal of Sociology and Social Work, 6(1), 34-40.

Laser-Maira, J., Huey, C., Castro, O., Ehrlich, K. (2016). Human Trafficking in Peru: Stakeholder Perceptions. International Social Work Journal, 3(1). https://doi.org/10.5296/ijsw. v3i1.8750

LaVerdiere, M. (2007). The use of music in therapy with children who have been sexually abused. In S. Brooke, (Ed.). The use of the creative therapies with sexual abuse survivors (pp. 207-234). Springfield, IL: Charles C. Thomas.

Lederer, L. J., \& Wetzel, C. A. (2014). Health consequences of sex trafficking and their implications for identifying victims in healthcare facilities. Annals of Health Law, 23, 61-91.

Lefevre, M. (2004). Playing with sound: The therapeutic use of music in direct work with children. Child \& Family Social Work, 9(4), 333-345. https://doi.org/10.1111/j.1365-2206. 2004.00338.x

Levine, J., \& Schumacher, U. (2017). Mental health issues in survivors of sex trafficking. Cogent Medicine, 4(1). https://doi.org/10.1080/2331205X.2017.1278841

Macy, R. J., \& Johns, N. (2011). Aftercare services for international sex trafficking survivors: Informing U.S. service and program development in an emerging practice area. Trauma, Violence, and Abuse, 12(2), 87-98. https://doi.org/10.1177/1524838010390709

Maslow, A. (1943). A theory of human motivation. Psychological Review, 50, 370-396. https://doi.org/10.1037/h0054346

Maslow, A. H. (1987). Motivation and personality (3rd ed.). Delhi, India: Pearson Education. Maney, G. M., Brown, T., Gregory, T., Mallick, R., Simoneschi, S., Wheby, C., \& Wiktor, N. (2011). Meeting the service needs of human trafficking survivors in the New York City metropolitan area: Assessment and recommendations.

McIntyre, B. L. (2014). More than just rescue: Thinking beyond exploitation to creating 
assessment strategies for child survivors of commercial sexual exploitation. International Social Work, 57(1), 39-63. https://doi.org/10.1177/0020872813505629

Naramore, R., Bright, M. A., Epps, N., \& Hardt, N. S. (2017). Youth arrested for trading sex have the highest rates of childhood adversity: A statewide study of juvenile offenders. Sexual Abuse, 29(4), 396-410. https://doi.org/10.1177/1079063215603064

Nicotera, N., \& Laser-Maira, J. (2017). Innovative Skills to Support Well-being and Resiliency in Youth. New York: Oxford University Press.

Oram, S., Khondoker, M., Abas, M., Broadbent, M., \& Howard, L. M. (2015). Characteristics of trafficked adults and children with severe mental illness: a historical cohort study. Lancet Psychiatry, 2(12), 1084-91. https://doi.org/10.1016/S2215-0366(15)00290-4

Ottisova, L., Smith, P., Shetty, H., Stahl, D., Downs, J., \& Oram, S. (2018). Psychological consequences of child trafficking: An historical cohort study of trafficked children in contact with secondary mental health services. PLoS one, 13(3), e0192321. https://doi.org/10.1371/ journal.pone.0192321

Palmer, E., \& Foley, M. (2017). 'I Have My Life Back': Recovering from child sexual exploitation. British Journal of Social Work, 47(4), 1094-1110. https://doi.org/10.1093/bjsw/ bcw020

Polaris. (2010). Identifying Victims of Human Trafficking: What to look for during a medical exam/consultation. Retrieved from https://humantraffickinghotline.org/resources/what-lookhealthcare-setting

Powell, C., Asbill, M., Louis, E., \& Stoklosa, H. (2018). Identifying gaps in humantrafficking mental health service provision. Journal of Human Trafficking, 4(3), 256-269. https://doi.org/10.1080/23322705.2017.1362936

Rafferty, Y. (2018). Mental health services as a vital component of psychological recovery for victims of child trafficking for commercial sex exploitation. American Journal of Orthopsychiatry, 88(3), 249-260. https://doi.org/10.1037/ort0000268

Rafferty, Y. (2013). Child trafficking and commercial sexual exploitation: A review of promising prevention policies and programs. American Journal of Orthopsychiatry, 83(4), 559-575. https://doi.org/10.1111/ajop.12056

Roe-Sepowitz, D. E. (2012). Juvenile entry into prostitution: The role of emotional abuse. Violence Against Women, 18(5), 562-579. https://doi.org/10.1177/1077801212453140

Schrader, E. M., \& Wendland, J. M. (2012). Music therapy programming at an aftercare center in Cambodia for survivors of child sexual exploitation and rape and their caregivers. Social Work \& Christianity, Journal of the North American Association of Christians in Social Work, 39(4), 390-406.

Steiner, J. J., Kynn, J., Stylianou, A. M., \& Postmus, J. L. (2018). Providing services to trafficking survivors: Understanding practices across the globe. Journal of Evidence Informed Social Work, 15(2), 151-169. https://doi.org/10.1080/23761407.2017.1423527

Surtees, R. (2006). Child trafficking in Southeastern Europe: Different forms of trafficking and alternative interventions. Tulane International Journal of Comparative Law, 14, 455-502. Stoklosa, H., MacGibbon, M., \& Stoklosa, J. (2017). Human trafficking, mental illness, and 
addiction: Avoiding diagnostic overshadowing. The AMA Journal of Ethic, 19(1), 23-34.

Swaner, R., Labriola, M., Rempel, M., Walker, A., \& Spadafore, J. (2016). Youth involvement in the sex trade: A national study. Center for Court Innovation. Retrieved from http://www.courtinnovation.org/research/youth-involvement-sextrade-national-study

Sweeney, A., Filson, B., Kennedy, A., Collinson, L., \& Gillard, S. (2018). A paradigm shift: relationships in trauma-informed mental health services. BJPsych advances, 24(5), 319-333. https://doi.org/10.1192/bja.2018.29

UNICEF (n.d.). Eastern and Southern Africa: child labour and commercial sexual exploitation. Retrieved from https://www.unicef.org/esaro/factsonchildren_5783.html

UNODC. (2016). Global Report on Trafficking in Persons 2016 (United Nations publication, Sales No. E.16.IV.6.

U.S. Department of Justice, Office of Juvenile Justice and Delinquency Prevention and National Academies (2013). Commercial sexual exploitation of children.

Varma, S., Gillespie, S., McCracken, C., \& Greenbaum, V. J. (2015). Characteristics of child commercial sexual exploitation and sex trafficking victims presenting for medical care in the United States. Child Abuse \& Neglect, 44, 98-105. https://doi.org/10.1016/j.chiabu.2015. 04.004

Walk Free Foundation (2014). The global slavery index.

Westwood, J., Howard, L. M., Stanley, N., Zimmerman, C., Gerada, C., \& Oram, S. (2016). Access to, and experiences of, healthcare services by trafficked people: Findings from a mixed-methods study in England. British Journal of General Practice, 66(652), e794-e801.

Williamson, E., Dutch, N. M., \& Clawson, H. J. (2008). National symposium on the health needs of human trafficking victims: Post-symposium brief. Washington, DC: Office of the Assistant Secretary for Planning and Evaluation, U.S. Department of Health and Human Services.

Williamson, E., Dutch, N. M., \& Clawson, H. J. (2010). Evidence-based mental health treatment for victims of human trafficking. U.S. Department of Health and Human Services, Office of the Assistant Secretary for Planning and Evaluation. Retrieved from https://aspe.hhs.gov/system/files/pdf/76116/index.pdf

\section{Copyright Disclaimer}

Copyright reserved by the author(s).

This article is an open-access article distributed under the terms and conditions of the Creative Commons Attribution license (http://creativecommons.org/licenses/by/3.0/). 